\title{
Prospective Evaluation of Two Dosing Equations for Theophylline in Premature Infants
}

\author{
Varsha Bhatt-Mehta, Pharm.D., Steven M. Donn, M.D., M. Anthony Schork, Ph.D., \\ Susan Reed, Pharm.D., and Cary E. Johnson, Pharm.D. \\ Study Objectives. To evaluate prospectively the ability of two equations that \\ we previously derived to predict maintenance theophylline dosages that \\ provide a serum theophylline concentration (STC) of $8 \mu \mathrm{g} / \mathrm{ml}$, the \\ midtherapeutic range for treating apnea of prematurity; and to determine \\ the number of further dosage adjustments and STC determinations \\ required to achieve the target concentration in infants in whom it was not \\ achieved initially. \\ Design. Prospective study.
}

Setting. A 37-bed neonatal intensive care unit.

Patients. Fifty-four infants $27-34$ weeks' gestational age requiring intravenous hydrous aminophylline.

Interventions. Patients received a loading dose of $6 \mathrm{mg} / \mathrm{kg}$ intravenous aminophylline, followed by a maintenance dosage calculated using one of the two derived equations. The basis for equation selection was the gestational age of the patient.

Measurements and Main Results. Patients were stratified into two age groups: 27-30 weeks' gestational age (34 infants) and 31-34 weeks' gestational age ( 20 infants). The overall success rate for both equations in achieving the target concentration was $74 \%$. When infants were stratified by gestational age, those dosed by Equation 1 had a $76 \%$ success rate and those dosed by Equation 2 had a $65 \%$ success rate. Overall, 14 of 54 infants received an average of 1.2 dosage adjustments. This represents more than a $50 \%$ reduction in the number of adjustments made before introduction of these equations.

Conclusions. The ability of our previously derived equations to produce an STC within the midtherapeutic range for treating apnea of prematurity was demonstrated in the majority of patients studied (74\%). Further, the number of subsequent dosage adjustments required to attain the target STC in infants who had failed to achieve this STC initially was significantly less than using older, more traditional regimens.

(Pharmacotherapy 1996;16(5):769-776)

From the College of Pharmacy and the Departments of Pharmacy (Drs. Bhatt-Mehta, Johnson, and Reed), Pediatrics and Communicable Diseases, Section of Neonatal-Perinatal Medicine (Dr. Donn), and Biostatistics (Dr. Schork), University of Michigan, Ann Arbor, Michigan. Manuscript received June 23, 1995. Accepted pending revisions August 1, 1995. Accepted for publication in final form December 2, 1995.

Address reprint requests to Varsha Bhatt-Mehta, Pharm.D., Department of Pharmacy Services, F5203, C.S. Mott Children's Hospital, 200 East Hospital Drive, Ann Arbor, MI 48109-0225.
Recurrent apnea is a common complication of prematurity, carrying with it a high risk of morbidity and even mortality. Apnea severe enough to produce cyanosis or bradycardia is a potentially serious threat to the central nervous system of any infant and is an expected event in low-birthweight infants. ${ }^{1}$ Repeated episodes lasting longer than 20 seconds are capable of causing irreversible neurologic damage secondary to hypoxia and acidosis, and eventually result in 
death if left untreated. ${ }^{2}$ The frequency of apnea increases with decreasing weight. It occurs in $25 \%$ of infants less than $2500 \mathrm{~g}$ and in $84 \%$ of infants less than 1000 g. ${ }^{1,3}$ It appears to decrease exponentially with increasing gestational age, occurring in the majority of infants born at 30 weeks' or less. ${ }^{4}$

Apnea can be treated with supportive or pharmacologic measures. Supportive therapy consists of sensory stimulation, oxygen administration, continuous positive airway pressure, or mechanical ventilation. ${ }^{5-7}$ Pharmacologically, methylxanthines are the primary agents of choice, and doxapram hydrochloride may be a second-line agent. ${ }^{5}$ Caffeine and theophylline stimulate the central respiratory center. Theophylline is the primary treatment for apnea of prematurity in the United States, primarily due to the availability of intravenous and oral preparations commercially, whereas caffeine preparations still require extemporaneous compounding. This sometimes becomes cumbersome at an institutional level and also does not guarantee product uniformity from one institution to another.

The mechanism of action of theophylline includes alteration of the sensitivity of the medullary respiratory center to carbon dioxide and improvement of contractility of respiratory muscles and recovery from fatigue. ${ }^{5}$ Theophylline decreases the frequency of apnea by increasing respiratory minute volume and the ventilatory response to carbon dioxide, and decreasing the frequency of hyperoxic and hypoxic episodes. ${ }^{8,9}$ With caffeine or theophylline, a significant decrease in the number and severity of apneic episodes can usually be seen within 24-48 hours, and continued treatment leads to complete control of primary apnea of prematurity in most cases. $^{5}$ Serum theophylline concentrations (STC) in the range of $6-13 \mu \mathrm{g} / \mathrm{ml}$ are effective. ${ }^{1,10,11}$ The drug's toxic effects are dose related and include gastrointestinal, cardiovascular, and neurologic symptoms, with intractable seizures at STC exceeding $20 \mu \mathrm{g} / \mathrm{ml}^{12}$

Although theophylline has been used in the treatment of apnea of prematurity for over 2 decades, no consensus exists as to the best method of predicting maintenance dosages in premature infants. Numerous small studies evaluated the agent's disposition in premature infants. ${ }^{10,11,13-19}$ The general dosing guideline they arrived at is a loading dose of $5.0-6.0 \mathrm{mg} / \mathrm{kg}$ followed by a maintenance dosage of 1.1-2.0 $\mathrm{mg} / \mathrm{kg}$ every 12 hours. Earlier ${ }^{20}$ we compared the accuracy, precision, and reliability of two published equations using postnatal age (PNA) as a variable ${ }^{21,22}$ to calculate the maintenance dosage of theophylline based on patients' disposition characteristics. We found that the equations were unreliable for predicting safe and effective maintenance dosages in premature infants. Subsequently we used the collected data to arrive at two new equations specific to the premature infant (Appendix) and targeted at achieving an STC of $8 \mu \mathrm{g} / \mathrm{ml}$.

We prospectively evaluated the accuracy with which the equations derived in our previous study ${ }^{20}$ were able to predict maintenance theophylline dosages that provide an STC of 8 $\mu \mathrm{g} / \mathrm{ml}$, the midtherapeutic range for treating apnea of prematurity. A second aim was to determine the number of further dosage adjustments and STC determinations required to achieve the target concentration in infants in whom it was not achieved initially. The hypothesis was that the new equations would produce an STC of $8 \mu \mathrm{g} / \mathrm{ml}$ or more in at least $66 \%$ of patients. Allowing infants to reach a therapeutic STC faster would reduce the time spent being apneic and hypoxemic, thus reducing morbidity from such events, and would require fewer dosage adjustments and subsequent STC determinations, thus decreasing blood loss and the need for transfusions, as well as risk of infection due to numerous venipunctures or heelsticks.

\section{Methods}

Fifty-four infants 27-34 weeks' gestational age requiring intravenous hydrous aminophylline were included in the study. This sample size allowed for observing a $15 \%$ or more decrease in the number of STC determinations in patients who achieved an STC of less than $8 \mu \mathrm{g} / \mathrm{ml}$ with an initial maintenance dosage. The new equations were designed to produce an STC of 8 $\mu \mathrm{g} / \mathrm{ml}$ with the initial maintenance dosage. The exclusion criterion was gestational age less than 27 weeks or greater than 34 weeks.

At our institution, intravenous aminophylline is routinely given before endotracheal extubation in premature infants 34 weeks' gestational age or less based on a previous report. ${ }^{23}$ Since theophylline is the standard treatment for apnea of prematurity and all premature infants at our institution follow the standard protocol, informed consent was not sought before entering patients into the study. However, the approval of 
the institutional review board was obtained.

All infants requiring periextubation aminophylline were enrolled and stratified into two age groups: $27-30(n=34)$ and $31-34(n=20)$ weeks' gestational age. These were based on the results of our previous study where the correlation between theophylline dosage and gestational age was best when infants were divided into less than and greater than 30 weeks' gestational age. The upper limit of 34 weeks was set based on our protocol.

All premature infants were given a standard 6$\mathrm{mg} / \mathrm{kg}$ intravenous loading dose of aminophylline dihydrate. For the younger group, the maintenance dosage of aminophylline was calculated based on Equation 1 and for the older group it was calculated based on Equation 2. The equations allowed the maintenance dosages to be calculated as $\mathrm{mg} / \mathrm{kg} / \mathrm{day}$ of theophylline. Adjustments were then made to allow for conversion from theophylline to aminophylline and also for the infants' weight. The final dosage was derived as $\mathrm{mg} /$ day of aminophylline. It was then divided into three equal doses that were administered at 8-hour intervals. The first maintenance dose was administered 8 hours after the loading dose. The loading dose as well as all maintenance doses were infused over 15-30 minutes using a syringe infusion pump.

Trough STCs were measured in all subjects just before the fourth maintenance dose of aminophylline. The STC was analyzed by fluorescence polarization immunoassay (TDx; Abbott Laboratories, Chicago, IL). Infants were followed as long as they were receiving intravenous aminophylline in the neonatal intensive care unit. Those not within the target range were investigated for possible etiologies for the subtherapeutic STC. Dosage adjustments made were recorded and new STCs were determined just before the fourth newly adjusted dose. Subjects were monitored for apnea and signs of theophylline toxicity. Any concurrent drug therapy or other treatments given for apnea of prematurity were recorded. Any tests performed to evaluate the apneic episodes were followed.

Data collected on each subject were PNA, gestational age, weight (at the beginning of treatment and around assessment of STC), STC, theophylline dosage based on equation calculations, and any dosage adjustments that were made to achieve therapeutic STC. Results of liver function tests and other treatments that may affect STC were also recorded.

Descriptive statistics including means and
Table 1. Patient Demographics ${ }^{a}$

\begin{tabular}{cccc}
\hline & $\begin{array}{c}\text { Gestational } \\
\text { Age } \\
\text { (wks) }\end{array}$ & $\begin{array}{c}\text { Postnatal Age } \\
\text { at Treatment } \\
\text { (wks) }\end{array}$ & $\begin{array}{c}\text { Weight at } \\
\text { Treatment } \\
\text { (kg) }\end{array}$ \\
\hline $27-30$ & $28.99 \pm 1.44$ & $0.86 \pm 0.83$ & $1.31 \pm 0.24$ \\
$31-34$ & $32.11 \pm 0.95$ & $0.33 \pm 0.16$ & $1.61 \pm 0.33$ \\
\hline
\end{tabular}

${ }^{\mathrm{a}}$ Expressed as mean $\pm \mathrm{SD}$.

standard deviations were computed. The frequency with which the two equations produced maintenance theophylline dosages with STC within the desired therapeutic range of 8 $\mu \mathrm{g} / \mathrm{ml}$ or greater was determined. Paired Student's $t$ test and repeated measures analysis of variance (ANOVA) were used to compare the new equations with the previously evaluated equations ${ }^{20}$ to determine if there was a statistically significant difference in the success rate.

We also calculated each patient's steady-state clearance $(\mathrm{mg} / \mathrm{kg} / \mathrm{hr})$ based on the actual dosage received $(\mathrm{mg} / \mathrm{kg} /$ day $)$ and measured steady state STC $(\mathrm{mg} / \mathrm{L})$. Using this steady-state clearance and the dosage generated by equation $\mathrm{A}$ or $\mathrm{B}$, the steady-state predicted STC was calculated for each patient. This predicted STC was plotted against the $\mathrm{mg} / \mathrm{kg} /$ day dosage calculated using each equation as well as the dosages obtained with the new equations.

\section{Results}

The 54 infants all received a loading dose of intravenous aminophylline $6 \mathrm{mg} / \mathrm{kg}$ (Table 1). Although Equations 1 and 2 were designed to achieve an STC of $8 \mu \mathrm{g} / \mathrm{ml}$, any serum concentration greater than $7.2 \mu \mathrm{g} / \mathrm{ml}$ was considered a therapeutic success because of a potential $10 \%$ instrumental variation in the analysis of serum theophylline concentrations in our laboratory. Only four infants in the younger group had an STC between 7.2 and $8 \mu \mathrm{g} / \mathrm{ml}$ and were classified as therapeutic successes. Twenty infants in this group who were declared therapeutic successes achieved an STC of $8 \mu \mathrm{g} / \mathrm{ml}$ or greater with the initial regimen based on Equation 1. No such patients were identified in the older group. That is, all infants who were therapeutic successes achieved an STC of $8 \mu \mathrm{g} / \mathrm{ml}$ or greater with the initial maintenance dosage calculated using Equation 2. We realize that this $7.2 \mu \mathrm{g} / \mathrm{ml}$ value (for a lower limit of $8 \mu \mathrm{g} / \mathrm{ml}$ ) is not ideal, but it is real, and clinicians must be aware of such practical problems and take them into 
consideration when interpreting laboratory data.

Whereas the equations were designed to achieve an STC of $8 \mu \mathrm{g} / \mathrm{ml}$, some patients would achieve an STC greater than that due to interpatient variability in theophylline metabolism. Thus, a dosing regimen was considered to be a therapeutic success if the STC achieved was 8 $\mu \mathrm{g} / \mathrm{ml}$ or greater and adjusted to $7.2 \mu \mathrm{g} / \mathrm{ml}$ as explained. The overall success rate for both equations in achieving a level of $7.2 \mu \mathrm{g} / \mathrm{ml}$ or greater was $74 \%$. When infants were stratified by gestational age, those dosed by Equation 1 had a $76 \%$ success rate and those dosed by Equation 2 had a $65 \%$ success rate.

A second aim of this study was to evaluate the number of dosage adjustments required by patients who did not achieve the target STC with the initial regimen. Of the 34 infants 27-30 weeks' gestational age, 10 had dosages adjusted 1-2 times to achieve the target concentration. Four of these 10 had an STC greater than 7.2 $\mu \mathrm{g} / \mathrm{ml}$ but were symptomatic with evidence of apnea or periodic breathing. Of the remaining six, five were symptomatic with an STC less than $7.2 \mu \mathrm{g} / \mathrm{ml}$. The tenth infant had an STC less than $7.2 \mu \mathrm{g} / \mathrm{ml}$ but was not symptomatic.

Of the 20 infants age 31-34 weeks' gestational age, 4 had dosages adjusted after the initial regimen. Of these four, two were symptomatic with evidence of apnea and were therapeutic failures with an STC less than $7.2 \mu \mathrm{g} / \mathrm{ml}$. In the remaining two, the STC was greater than 7.2 $\mu \mathrm{g} / \mathrm{ml}$ in one and below target concentration in the other.

Overall, 14 of 54 patients received an average of 1.2 dosage adjustments. This represents more than a $50 \%$ reduction in the number of adjustments that were made before introduction of these equations.

We used the patient population from the prospective study and predicted the $\mathrm{mg} / \mathrm{kg} / \mathrm{day}$ dosage that we would achieve using the equations of Hendeles et $\mathrm{al}^{24}$ (Equation $\mathrm{A}$ ) and Nassif et $\mathrm{al}^{21}$ (Equation B). Both equations were applied to both groups. The mean dosage generated from these equations was compared with the mean dosage generated by the new equations using repeated measures ANOVA (Table 2). All three mean dosages were significantly different $(\mathrm{p}<0.05)$. Pairwise Student's $t$ test was used to compare the mean dosage from the new equations with each of the mean dosages from Equations $A$ and $B$ for each group of patients. The means were again significantly different for the younger group
Table 2. Success Rates of Dosing Equations from the Retrospective Study ${ }^{20}$ and Current Study Using Patient Demographics from the Prospective Study Population

\begin{tabular}{|c|c|c|}
\hline $\begin{array}{l}\text { Equations } \\
\text { Compared }\end{array}$ & $\begin{array}{l}\text { Mean Dosage } \\
\text { Using Patient } \\
\text { Demographics } \\
\text { from the } \\
\text { Prospective Study } \\
\text { (mg/kg/day) }\end{array}$ & $\begin{array}{c}\text { Repeated Measures } \\
\text { ANOVA and } \\
\text { Paired } t \text { Test }\end{array}$ \\
\hline $\begin{array}{l}27-30 \text { wks' } \\
\text { gestational age }\end{array}$ & $=$ & $\begin{array}{c}\text { ANOVA } \mathrm{p}<0.05 \\
\text { Paired } t \text { test }\end{array}$ \\
\hline Equation 1 & $9.8 \pm 2.2$ & 1 vs $\mathrm{A} \mathrm{p}=0.000$ \\
\hline Equation A & $5.15 \pm 0.16$ & 1 vs $B p=0.0004$ \\
\hline Equation B & $8.24 \pm 0.24$ & A vs $B p=0.000$ \\
\hline $\begin{array}{l}\text { 31-34 wks' } \\
\text { gestational age }\end{array}$ & & $\begin{array}{c}\text { ANOVA } \mathrm{p}<0.05 \\
\text { Paired } t \text { test }\end{array}$ \\
\hline Equation 2 & $10.4 \pm 2.2$ & 2 vs $A$ p $=0.000$ \\
\hline Equation $\mathrm{A}$ & $5.07 \pm 0.04$ & 2 vs $B$ p $=0.0002$ \\
\hline Equation $B$ & $8.1 \pm 0.05$ & $A$ vs $B p=0.000$ \\
\hline
\end{tabular}

$(\mathrm{p}=0.0004)$ and the older group ( $\mathrm{p}=0.0002)$.

Figures 1 and 2 are scatter plots of dosages calculated by the new equations and the corresponding plasma STCs. Figures 3-6 show the predicted steady-state STC that would have resulted if the dosage recommended by Equation A or B was administered. The mean predicted concentrations were $6.5 \pm 1.3 \mu \mathrm{g} / \mathrm{ml}(27-30 \mathrm{wks})$ and $6.9 \pm 1.6 \mu \mathrm{g} / \mathrm{ml}(31-34 \mathrm{wks})$ for Equation $\mathrm{A}$ and $10.4 \pm 2.1 \mu \mathrm{g} / \mathrm{ml}(27-30 \mathrm{wks})$ and $11.3 \pm 2.5$ $\mu \mathrm{g} / \mathrm{ml}$ (31-34 wks) for Equation B. The corresponding STC values for the new equations were $8.3 \pm 2$ and $8.3 \pm 1.8 \mu \mathrm{g} / \mathrm{ml}$, respectively, for the two age groups.

Most of the infants in both age groups dosed based on Equation $B$ would have been in the acceptable range of $7.2-12 \mu \mathrm{g} / \mathrm{ml}$ range. Although this result compares reasonably well with STC obtained using the new equations, a fair number of patients still would achieve concentrations as high as $17 \mu \mathrm{g} / \mathrm{ml}$, which are considered to be in the toxic range for treatment of apnea of prematurity. The STC produced by Equation A were consistently below $7.2 \mu \mathrm{g} / \mathrm{ml}$.

Concomitant drugs during the study period included antibiotics and, occasionally, phenobarbital. We give phenobarbital routinely for intraventricular hemorrhage prophylaxis in all premature infants weighing less than $1800 \mathrm{~g} .{ }^{25}$ However, this is a limited time protocol and includes a loading dose of $20 \mathrm{mg} / \mathrm{kg}$ followed by standard maintenance dosage of $5 \mathrm{mg} / \mathrm{kg} /$ day for 4 days after birth. This short course of phenobarbital is insufficient to produce enzyme induction. ${ }^{18}$ Most infants had stopped receiving 
phenobarbital by the time they were ready for extubation.

\section{Discussion}

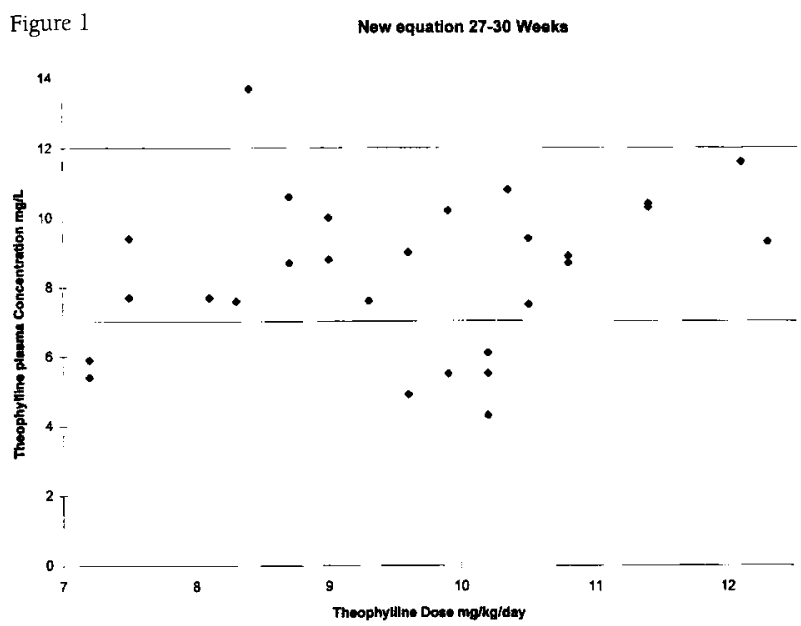

Figure 2

New Equation 31-34 Wooks

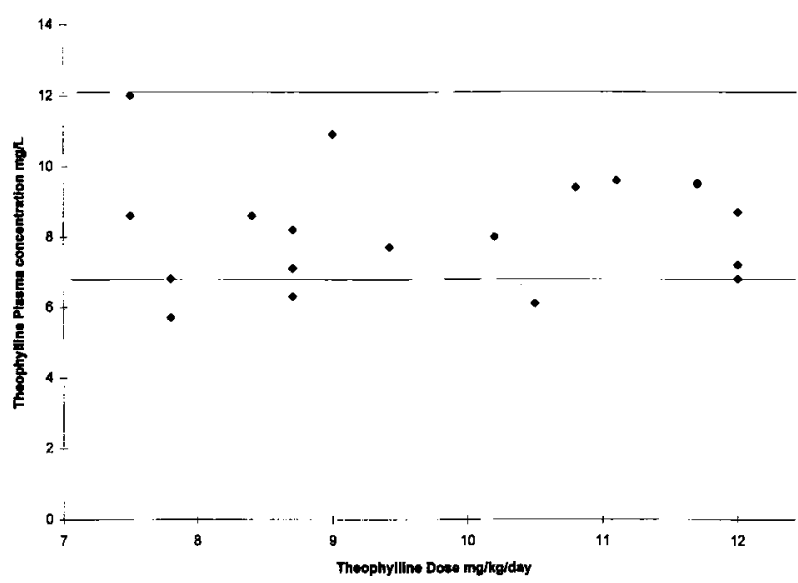

Figure 3

Equation A (Handoles) for 27-30 Woeke

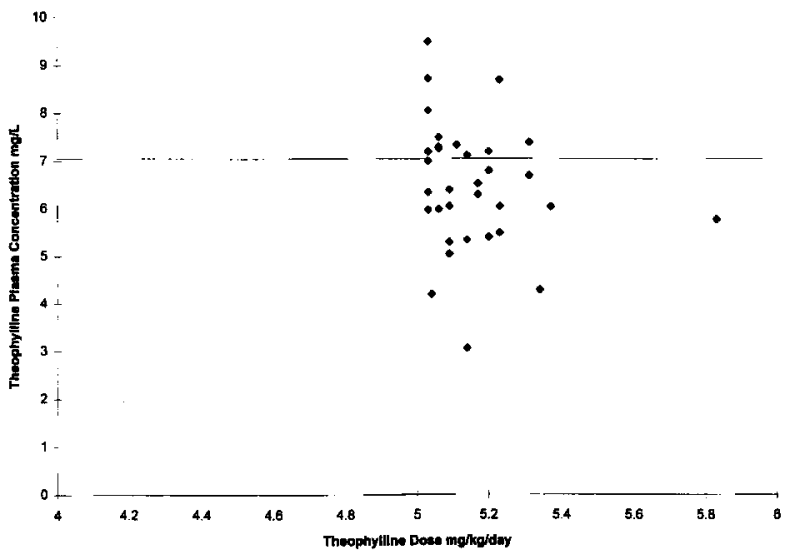

Dosage guidelines currently available for calculating theophylline maintenance dosages have to be evaluated for administration for apnea of prematurity, since the studies included widely

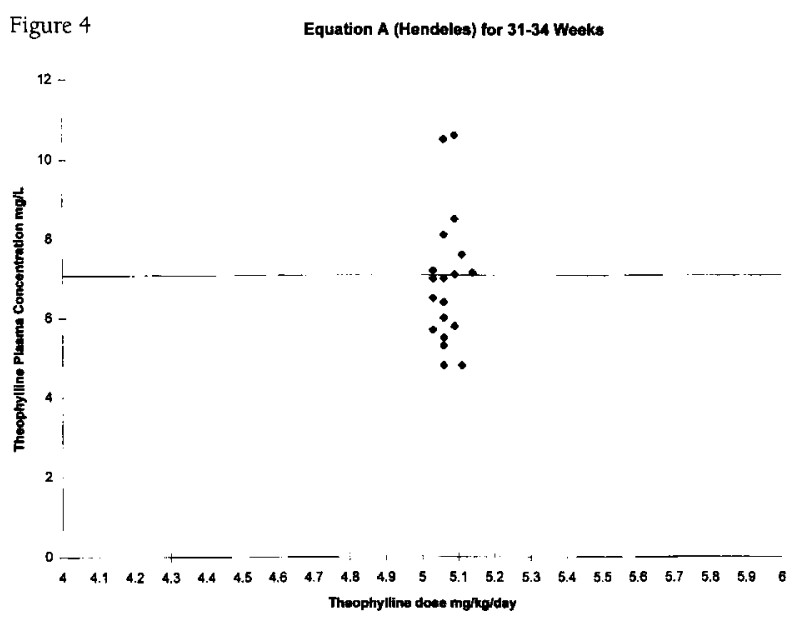

Figure 5
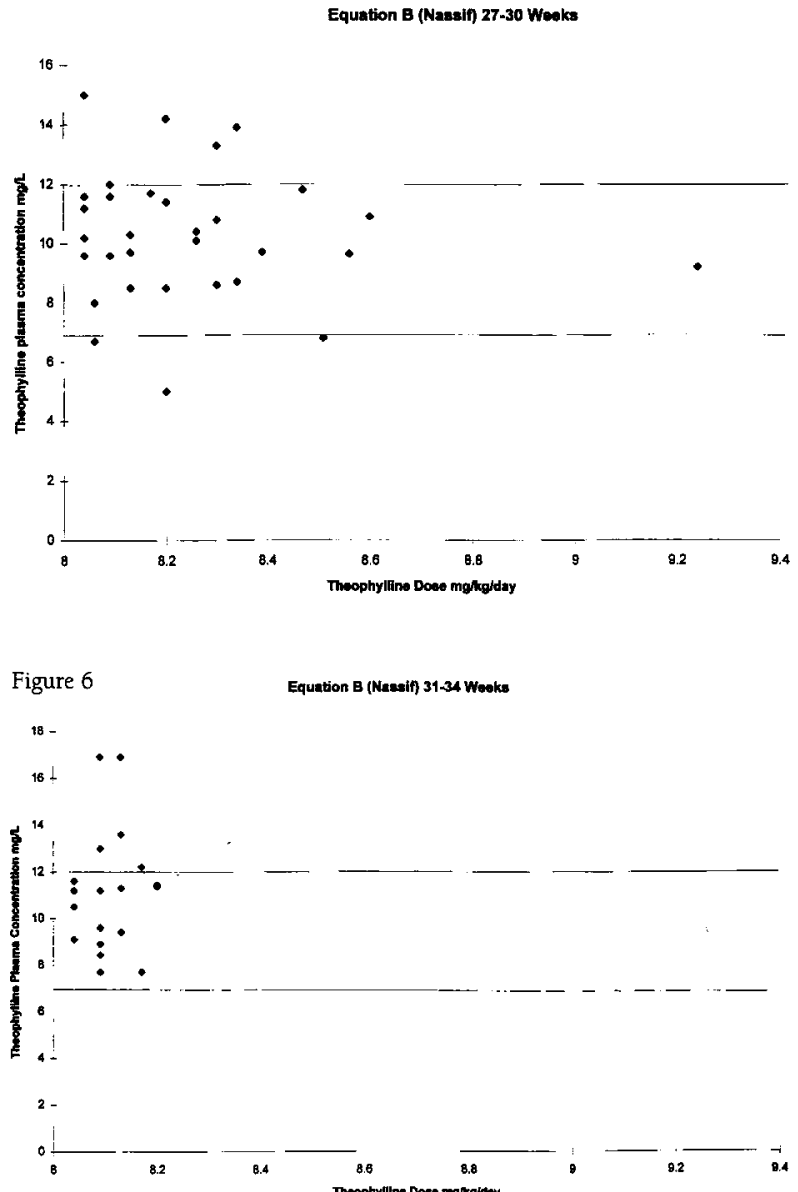

Figures 1-6. Scatter plots of calculated serum theophylline concentrations vs recommended dosages for the new equations (plots 1 and 2) and the Hendeles et al ( 3 and 4) and Nassif et al (5 and 6) equations. Horizontal lines in the plot at concentrations of 7.2 and $12 \mu \mathrm{g} / \mathrm{ml}$ represent the therapeutic range aimed at in this study and is the generally accepted range for treatment of apnea of prematurity. 
variable patient populations, dosing intervals, and routes and methods of administration (intermittent vs continuous infusions). 21, 24, 26 Most of the guidelines are based on the clearance of theophylline in newborn infants. Clearance depends on volume of distribution and the elimination rate constant, both of which change with maturation. ${ }^{18}$ Previous studies evaluating theophylline pharmacokinetics in newborn infants showed that the most important variables for predicting theophylline clearance are weight and PNA. Both are related to the development of the newborn and determinants of the functional activity of the eliminating system. ${ }^{10,21,27-29}$ Weight and gestational age are highly correlated, indicating that factors such as gestational age should also be important predictors of theophylline clearance. ${ }^{18}$

Since maturation is a continuous process and occurs at a variable rate in newborns, the volume of distribution and elimination rate constant reported in the literature vary depending on the ages of the infants. Several studies developed empiric dosage guidelines based on weight and pharmacokinetics. These dosages vary from 1.1 $\mathrm{mg} / \mathrm{kg}$ every 8 hours to $1-4 \mathrm{mg} / \mathrm{kg}$ every 12 hours. ${ }^{10,11}$ Current recommendations of the Food and Drug Administration consist of a loading dose equal to $1 \mathrm{mg} / \mathrm{kg}$ for every $2-\mu \mathrm{g} / \mathrm{ml}$ desired increase in STC and a maintenance dosage of $1 \mathrm{mg} / \mathrm{kg}$ every 12 hours in premature infants 40 weeks' postconception age (PCA) or younger, or $1-2 \mathrm{mg} / \mathrm{kg}$ every 12 hours for term infants (either at birth or 40 wks' PCA). ${ }^{30}$ However, these guidelines have been criticized as too conservative, often resulting in STCs below 6 $\mu \mathrm{g} / \mathrm{ml}^{26,31}$

Alternatively, dosing equations derived for administering theophylline to asthmatic patients were used in an attempt to individualize dosages in infants with apnea of prematurity. In a study of infants 6-48 weeks' PNA with asthma, an equation was generated by linear regression to express a relationship between PNA and oral theophylline requirement. ${ }^{21}$ Another such equation incorporates PNA as a variable and aims for an STC between $7-13 \mu \mathrm{g} / \mathrm{ml}^{22}$ In a retrospective study of 52 infants 4.5-54.3 weeks' PNA, three equations were compared that incorporated either PNA or PCA to calculate theophylline maintenance dosages. The patients received theophylline by continuous intravenous infusion. The observed theophylline clearance and the dosages derived from each equation were used to determine the projected steady-state STC.
Of these equations, the two based on PNA were superior, with one better at achieving the greatest proportion of STC within the therapeutic range of $10-20 \mu \mathrm{g} / \mathrm{ml}$ and the other better when serum concentrations less than $10 \mu \mathrm{g} / \mathrm{ml}$ were desired. ${ }^{32}$

In summary, the majority of methods for dosing theophylline for the treatment of apnea of prematurity are empiric. They are based primarily on weight, or dosages are calculated from equations incorporating PNA in infants requiring theophylline for the treatment of asthma. The age range of the patients and the therapeutic STCs obtained in these studies are different from those involved in apnea of prematurity.

Proposed dosing guidelines based on gestational age, weight, and PNA were able to produce a therapeutic STC in the majority of premature infants evaluated. The overall success rate for the two equations of $74 \%$ was consistent with the hypothesis that the equations would produce an STC of $8.0 \mu \mathrm{g} / \mathrm{ml}$ in at least $66 \%$ of these premature infants. Using patient data from the prospective study, all three equations were statistically different when compared using repeated measures ANOVA for both age groups. Equation B performed much better than Equation $A$ in predicting a daily dose closer to the new equations.

This result is different from our retrospective study, in which Equation A was much more successful than Equation B in producing target STC. There are several reasons for this. The retrospective and prospective equations were compared for their ability to produce the target STC using different patient populations; however, when patient data from the prospective study were fit to the previous Equations $\mathrm{A}$ and $\mathrm{B}$, the ability of these equations to predict the dosage that would produce an STC close to that produced by Equation 1 or 2 was determined. Equation $B$ did not perform well in the retrospective study because our target STC was 8 $\mu \mathrm{g} / \mathrm{ml}$ and it produced a higher STC, thus requiring us to declare a lot of patients as failures. In the prospective study, the STC was 8 $\mu \mathrm{g} / \mathrm{ml}$ or higher, up to a maximum of $12 \mu \mathrm{g} / \mathrm{ml}$ considered the acceptable normal range for treatment of apnea of prematurity, and increasing the target range increased the success rate. Finally, none of the equations in the retrospective study incorporated gestational age as a variable, and this seems to have major influence on the dosage generated by the new equations.

The greater than $50 \%$ reduction in the number of subsequent dosage adjustments necessary to 
achieve the desired STC in infants with an initial low STC was also consistent with the hypothesis that these equations would result in $15 \%$ or more reduction in the number of dosage adjustments required after the initial dose.

Attempts to identify the cause of STC less than $7.2 \mu \mathrm{g} / \mathrm{ml}$ in both age groups did not reveal any obvious reasons other than interindividual variation. The PNA and gestational age were comparable for all infants in each group who had STC below the desired level after the initial regimen and received dosage adjustments.

Some of these infants were receiving simultaneous phenobarbital, but this was not different from the infants who had achieved STC of 7.2 $\mu \mathrm{g} / \mathrm{ml}$ or higher with the initial dose. Phenobarbital induces theophylline metabolism in adults after administration for at least 1 month. ${ }^{33}$ Several investigators showed no to minimal effect of phenobarbital on theophylline clearance in children, especially with short courses such as the given to our patients for prophylaxis against intraventricular hemorrhage. ${ }^{34,35}$ Although phenobarbital is thought to be a nonspecific inducer of the entire cytochrome P-450 system in adults, ${ }^{36}$ such effects have not been observed in newborn infants receiving short-term treatment. ${ }^{18}$

The disposition of theophylline in premature and term newborn infants differs greatly from that of children and adults because of altered metabolism. In newborn infants, renal elimination of unchanged drug and methylation of theophylline to caffeine are the predominant pathways of elimination, whereas the oxidation and demethylation pathways leading to the usual metabolites seen in adults are barely functioning. ${ }^{12}$ Immaturity of the hepatic cytochrome P-450 mixed-function oxidase system is the reason for this altered metabolism and results in a very long half-life of theophylline in infants (13-29 hrs)..$^{1,5}$, $12,29,37$

The half-life of caffeine is also prolonged and can range from 100-200 hours in a newborn. ${ }^{12}$ Metabolic rates are highly variable between and within newborn infants secondary to the different degrees of maturity and rapid changes in hepatic enzyme systems. ${ }^{5}$ As the infant matures, the halflife of theophylline decreases. The percentage of theophylline converted to caffeine remained unchanged in infants 28-42 weeks PCA. ${ }^{38}$ Caffeine and theophylline are both active drugs, with synergistic efficacy and toxicities further complicating the dosing of theophylline in the newborn. ${ }^{12}$ Overall, the small number of infants in each group who did not achieve the desired
STC with initial dosing regimen is best explained by interindividual variation in theophylline metabolism in the first year of life.

Equations that can consistently achieve an STC within the therapeutic range are valuable for use in preterm infants because of the narrow therapeutic range and the interindividual variations in metabolism of theophylline in the newborn. By successfully achieving a level of 8.0 $\mu \mathrm{g} / \mathrm{ml}$ in $72 \%$ of infants gestational age $27-34$ weeks, the need for numerous STC determinations is reduced. Reaching a therapeutic STC quickly benefits the preterm infant by reducing delays in attaining adequate drug concentrations in plasma. Decreasing the number of blood draws saves both time and the cost of determining the levels. Also, the infant is spared the trauma of blood sampling, the loss of blood for testing, and a possible reduction in the number of transfusions and hence blood donor exposures.

\section{Conclusion}

The equations evaluated in this study produced results consistent with our hypothesis. A significant number of infants still did not achieve therapeutic STC and remained symptomatic. No specific patient characteristics other than interindividual variations in theophylline metabolism could be identified as cause of failure to achieve target concentrations with initial maintenance dosage. Appropriate use of these equations should result in target STCs in the majority of premature infants.

\section{Appendix. Dosing Regimen and Equations}

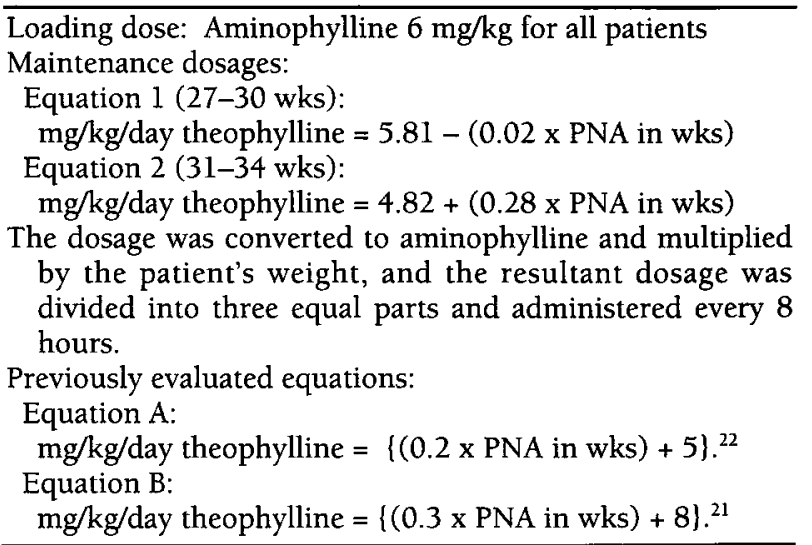

\section{References}

1. Shannon DC, Gotay F, Stein IM, Rogers MC, Todres ID, Moylan FMB. Prevention of apnea and bradycardia in low birth weight infants. Pediatrics 1975:55:589-94. 
2. Alden ER, Mandelkorn T, Woodrum DE, Wennberg RP, Parks CR, Hodson WA. Morbidity and mortality of infants weighing less than 1000 grams in an intensive care nursery. Pediatrics 1972;50:40-9.

3. Daily WJR, Klaus M. Apnea in premature infants: monitoring incidence, heart rate changes, and effect of environmental temperature. Pediatrics 1969;43:510-18.

4. Henderson-Smart DJ, Pettigrew AG, Campbell DJ. Clinical apnea and brainstem neural function in preterm infants. N Engl J Med 1983;308:353-7.

5. Martin RJ, Miller MJ, Carlo WA. Pathogenesis of apnea in preterm infants. J Pediatr 1986;109:733-41.

6. Gerhardt T, McCarthy J, Bancalari E. Effect of aminophylline on respiratory center and reflex activity in premature infants with apnea. Pediatr Res 1983;17:199-201.

7. Uauy R, Shapiro DL, Smith B, Warshaw JB. Treatment of severe apnea in prematures with orally administered theophylline. Pediatrics 1975;55:595-8.

8. Davi MJ, Sankaran $\mathrm{K}$, Simons KJ, et al. Physiologic changes induced by theophylline in the treatment of apnea in preterm infants. J Pediatr 1978;92:91-5.

9. Peabody J, Neese AL, Lucey JF, et al. Decreased hypoxic, hyperoxic and bradycardic episodes as responses of neonates to theophylline. Pediatr Res 1977;11:419.

10. Aranda JV, Sitar DS, Parsons WD, et al. Pharmacokinetic aspects of theophylline in premature newborns. $\mathrm{N}$ Engl J Med 1976;295:413-16.

11. Giacoia G, Jusko WJ, Menke J, et al. Theophylline pharmacokinetics in premature infants with apnea. J Pediatr 1976;89:829-32.

12. Cummiskey JM, Popa V. State-of-the-art: pharmacologictherapeutic update, theophyllines: a review. J Asthma 1984;21:243-57.

13. Stile IL, Zolfaghari S, Hiatt IM, et al. Pharmacokinetics of theophylline in premature infants on the first day of life. Clin Ther 1986;8:336-41.

14. Takieddine FN, Tserng K, King KC, et al. Postnatal development of theophylline metabolism in preterm infants Semin Perinatol 1981;5:351-8.

15. Estelle F, Simons R, Rigatto $H$, et al. Pharmacokinetics of theophylline in neonates. Semin Perinatol 1981;5:337-45.

16. Kraus DM, Fischer JH, Reitz SJ, et al. Alterations in theophylline metabolism during the first year of life. Clin Pharmacol Ther 1993;54:351-9.

17. Gal P, Boer H, Toback J, et al. Effect of asphyxia on theophylline clearance in newborns. South Med J 1982;75:836-8.

18. Moore ES, Faix RG, Banagale RC, et al. The population pharmacokinetics of theophylline in neonates and young infants. J Pharmacokinet Biopharm 1989;17:47-66.

19. Jones RAK, Baillie E. Dosage schedule for iv aminophylline in apnoea of prematurity, based on pharmacokinetic studies. Arch Dis Child 1979;54:190-3.

20. Bhatt-Mehta V, Johnson CE, Donn SM, Theisen V. Accuracy and reliability of dosing equations to individualize theophylline treatment in apnea of prematurity. Pharmacotherapy $1995 ; 15$ :
246-50.

21. Nassif EG, Weinberger MN, Shannon $D$, et al. Theophylline disposition in infancy. J Pediatr 1981;98:158-60.

22. Anonymous. Theophylline. In: Rowe PC, ed. Johns Hopkins, the Harriet Lane handbook, 12th ed. Chicago: Year Book, $1991: 237$.

23. Viscardi RM, Faix RG, Nicks JJ, Grasela TH. Efficacy of theophylline for prevention of post-extubation respiratory failure in very low birth weight infants. J Pediatr $1985 ; 107: 469-72$.

24. Hendeles L, Weinberger M, Johnson G. Theophylline. In: Evans WE, Schentag JJ, Jusko WJ, eds. Applied pharmacokinetics. San Francisco: Applied Therapeutics, 1980:95-138.

25. Donn SM, Roloff DW, Goldstein GW. Prevention of intraventricular hemorrhage in preterm infants by phenobarbitone. Lancet $1981 ; 2: 215-17$.

26. Anonymous. Use of theophylline in infants. FDA Drug Bull 1985;15:16-17.

27. Lonnerholm G, Lindstrom B, Paalow L, Sedin G. Serum theophylline and caffeine clearance during first year of life. Eur J Clin Pharmacol 1983;24:371-80.

28. Gilman JT, Gal P, Levine RS, Hersh CB, Erkan NV. Factors influencing theophylline disposition in 179 newborn infants. Ther Drug Monit 1986;8:4-10.

29. Bada HS, Khanna NN, Somani SM, Tin TT. Interconversion of theophylline and caffeine in newborn infants. J Pediatr 1979;94:993-5.

30. Gilman JT, Gal P. Inadequacy of FDA guidelines for theophylline use in neonates. Drug Intell Clin Pharm 1986;20:481-4.

31. Murphy JE, Erkan NV, Fakhreddine F. New FDA guidelines for theophylline dosing in infants [letter]. Clin Pharm 1986;5:16.

32. Hogue SL, Phelps SJ. Evaluation of three dosing equations in infants less than or equal to one year of age. Clin Res 1990;38:982A.

33. Landay RA, Gonzalez MA, Taylor JC. Effect of phenobarbital on theophylline disposition. J Allergy Clin Immunol 1978;62:27-9.

34. Yeung CY, Tam LS, Chan A, Lee KH. Phenobarbitone prophylaxis for neonatal hyperbilirubinemia. Pediatrics 1971:48:372-6.

35. Valdes OS, Maurer HM, Shumway CN, Draper DA, Hossaini AA. Controlled clinical trial of phenobarbital and/or light in reducing neonatal hyperbilirubinemia in a predominantly negro population. J Pediatr 1971;79:1015-17.

36. Aranda JV, Grondin D, Sasynick BI. Pharmacologic considerations in the therapy of neonatal apnea. Pediatr Clin North Am 1981;28:113-33.

37. Grasela TH, Donn SM. Neonatal population pharmacokinetics of phenobarbital derived from routine clinical data. Dev Pharmacol Ther 1985;8:374-83.

38. Tserg K, Takieddine FN, King KC. Developmental aspects of theophylline metabolism in premature infants. Clin Pharmacol Ther 1983;33:522-8. 